\title{
Relationship Between Internal and External Training Load in Field Hockey
}

Katrine Tuft ${ }^{1}$ and Mykolas Kavaliauskas ${ }^{1}$.

${ }^{1}$ School of Applied Sport Sciences, Edinburgh Napier University.

\section{ABSTRACT}

Training load monitoring in team sports is important in order to plan and evaluate training strategies and ensure optimal performance. Integration of internal and external training load measures into a single training efficiency metric reduces the effect of confounding variables on training loads. The purpose of this study was to generate a training efficiency metric to evaluate in-season field hockey training. Further, the relationship between players' perceived wellness the training efficiency metric was determined. Internal (training impulse and session rating of perceived exertion; TRIMP and SRPE) and external (total distance, high-speed distance, acceleration load, high-power distance, metabolic work, mechanical work, and impulse) training load was collected over a 6-week period for 11 male national level field hockey players $(21.1 \pm 1.2$ years, $178.7 \pm 8.6 \mathrm{~cm}, 4.6 \pm 6.3 \mathrm{~kg}$ ). The relationships between internal and external training load were assessed, and two training efficiency models were generated through mixed model analyses using SRPE and TRIMP. Subsequently, the relationships between training efficiency and perceived wellness were examined. The statistical analyses determined that total distance, high-speed distance, high-power distance, and metabolic work $(r=0.311-0.573)$ were included in the TRIMP training efficiency model. The sRPE training efficiency model included total distance, high-speed distance, high-power distance, metabolic work, and mechanical work $(r=0.329$ 0.757). Moreover, neither of the training efficiency models were related to daily cumulative wellness scores (TRIMP: $r=-0.046 ; p=0.336$; sRPE: $r=$ -0.034; $p=0.370$ ). The study showed that the sRPE training efficiency model provided a better reflection of in-season field hockey training demands than the TRIMP model. Additionally, practitioners are not advised to adjust training based on acute changes in players' perceived wellness.

Keywords: field hockey, athlete monitoring, global positioning system, heart rate, rating of perceived exertion.

\section{INTRODUCTION}

Appropriate training loads are necessary to successfully maintain and improve performance in sports $(32,41)$. Field hockey saw a substantial increase in playing volume and intensity after introducing 15-minute quarters instead of the original 35-minute halves in 2015 (42). Therefore, greater training loads are required to achieve the desired performance during games. However, poorly planned training cycles with inappropriately high training loads may have the opposite effect and limit performance improvements and increase the risk of injury and non-functional overreaching $(20,23,37)$. Therefore, monitoring the training loads completed by players can provide further insight into their training status and accumulated fatigue $(29,52)$.

Training load (TL) can be described as occurring externally or internally relative to each individual player (23). Advances in microtechnology, such as global positioning system (GPS) units have made measuring a large variety of external TL variables possible (29). However, individual responses to this training stimulus differ between players and is better reflected by internal TL $(2,8,53)$, such as heart rate $(H R)$ and session rating of perceived exertion (sRPE, 22). Banister (6) introduced a HR-derived metric of training impulse (TRIMP) as a universal measure of internal TL. Though, further adaptions 
of Banister's TRIMP are available, these provide similar TL values as Banister's TRIMP $(9,50)$ or require greater resources and scientific expertise to implement (39). The validity of Banister's TRIMP has been demonstrated by a dose-response relationship between TRIMP and changes in maximal oxygen consumption (53) and fitness test scores (18). Despite this, researchers have questioned its accuracy during intermittent exercise $(12,32)$. Conversely, sRPE demonstrates a good reflection of the demands of intermittent training as it reflects players' subjective feeling of training stimuli $(26,33)$. Additionally, the use of tailored wellness questionnaires has become important to support athlete preparation (48). Daily wellness scores likely affect same-day performance (24) and may therefore be used to supplement training monitoring. Coyne et al. (16) advocated for the integration of wellness, and internal and external TL in multivariate models of training efficiency. Integrated training efficiency models may limit the effects of contextual and environmental factors and differences in player fitness $(8,21)$ and therefore provide a more valid measure of $T L$.

Simple training efficiency models have been used in football to assess changes in fitness and recovery during pre-season $(2,13)$. However, the TL obtained with these models likely do not represent the full demands of training as external TL measures were limited to total and high-speed distance (1). More complex models including multiple external TL measures have been created which may better reflect the demands experienced by players (18, 38). Lacome et al. (38) predicted HR using total distance, high-speed and very high-speed distance, velocity load, force load, and mechanical work measured during football training. The authors were able to estimate changes in aerobic fitness using the difference in predicted and actual HR. However, due to the intermittent nature of many team sports, the use of $\mathrm{HR}$ alone could provide a less accurate reflection of training demands. Conversely, the inclusion of TRIMP and SRPE in the model proposed by Delaney, Duthie et al. (18) took into account the demands of intermittent training. The authors observed moderate to nearly perfect relationships between both internal TL measures and total distance, high-speed distance, acceleration-based load, high-metabolic power distance, metabolic and mechanical work, and impulse in rugby league. Moreover, validation of the model was demonstrated through large and nearly perfect relationships with maximal aerobic running speed. In a follow-up study Delaney, McKay et al. (19) did not observe significant relationships between their training efficiency model and perceived stress, muscle soreness, or hours of sleep in football. Based on their earlier results (18) the model was limited to include mechanical work and impulse. However, the model may not have been appropriate for use in football, as differences between the playing demands of rugby and football likely produce distinct relationships between internal and external TL (54). Moreover, cumulative wellness scores are significantly related to external and internal TL in team sports, including field hockey $(13,31,46)$, and may therefore influence players' athletic performance. Therefore, including a cumulative wellness score rather than separate wellness measures may be advantageous.

Though previous models have shown potential during pre-season, they may not reflect the TLs of inseason training due to differences in training intensity (34). Training monitoring is therefore arguably more important during the in-season period as it makes up the majority of a season. Despite this, no training efficiency model has been proposed for use in field hockey during this period. Therefore, the aim of this study was to examine the relationship between internal TL (TRIMP and SRPE) and multiple measures of external TL during the in-season period in field hockey. The most appropriate external TL measures were included in a training efficiency model to inform sports practitioners on the demands of their training. A second aim was to investigate the relationship between the training efficiency model and cumulative wellness scores, to assess whether the model was affected by changes in acute changes in perceived tiredness, stress, and muscle soreness. It was hypothesised that a positive relationship exists between internal TL and total distance, high-speed distance, acceleration-based load, high-metabolic power distance, metabolic work, mechanical work, and impulse. Moreover, it was hypothesised that cumulative wellness score was positively related to same-day training efficiency score.

\section{METHODS}

\section{Participants}

A sample of 11 male national level field hockey players were recruited for the study (age $=20.7 \pm$ 1.4 years, height $=178.7 \pm 7.4 \mathrm{~cm}$, mass $=74.6$ $\pm 6.3 \mathrm{~kg}$, and $30-15 \mathrm{IFT}=20.8 \pm 0.7 \mathrm{~km} \cdot \mathrm{h}-1)$. Prior to the commence of the study participants provided written informed consent and were illness and injury free at the time of the study. Ethical approval was 
granted by the university. One participant was excluded due to missing more than $25 \%$ of training sessions (four sessions), leaving a sample of 10 participants $(20.9 \pm 1.3$ years; $178.7 \pm 7.8 \mathrm{~cm}$; 74.6 $\pm 6.3 \mathrm{~kg} ; 20.8 \pm 0.7 \mathrm{~km} \cdot \mathrm{h}-1)$.

\section{Protocol and Equipment}

Data was collected during 13 field-based training sessions over 8 weeks during the in-season period. All training sessions were performed on the same water-based AstroTurf pitch at the same time (ambient temperature 1.0-10.0 ${ }^{\circ} \mathrm{C}$ ). Movement and $\mathrm{HR}$ data were collected using inertial measurement units (Optimeye S5, Catapult Sports, Australia) and paired Polar T31 coded transmitter bands (Polar Electro, Finland) with a sampling frequency of $10 \mathrm{~Hz}$. Validity of the inertial measurement units have been established previously in team sports (56). To ensure reliability of the measurements, each participant was assigned the same units every session located in a harness between the scapulae (44). RPE scores were collected from the participants separately using the Borg CR-10 scale (7) within 30 minutes of the end of sessions. The participants have routinely used the equipment and CR-10 scale in training, and therefore no familiarisation was performed. The start and end of each training drill was recorded to allow data analysis of these periods. Only running-based drills were considered, due to the lower accuracy of external load measurements during non-runningbased drills (e.g. penalties or short corners) (5).

The players' fitness levels were assessed the first week of testing using the 30-15 Intermittent Fitness Test (30-15IFT), where fitness was determined as maximal running velocity. The 30-15 IFT was carried out on a water-based AstroTurf field according to the protocol described by Buchheit (11). The test has good test-retest reliability and validity in football (intraclass correlation $=0.91$ ) and have been used to assess fitness in elite field hockey (35). No familiarisation session was conducted as the test is part of the teams' regular testing regimen.

\section{Wellness Questionnaire}

A 3-item wellness questionnaires were administered on training days between the hours of 8:00 and 10:00 AM to minimise athlete burden and improve validity $(10,48)$. The questionnaire was intended to enhance compliance and was designed specifically for the participant group $(29,48)$. The questionnaire included ratings of general stress, tiredness, and muscle soreness. The items were chosen based on their association with internal and external $T L$ and have previously been used in team sports $(15,24$, $25,49)$. Each question was scored on a 5-point scale, where scores of 1 indicated a poor rating and scores of 5 indicated a good rating. The scores were subsequently summated to give a cumulative wellness score, where low and high cumulative scores indicated poor and good wellness scores, respectively.

\section{Data Analysis}

\section{Internal TL}

After each training session, the raw HR data was imported to Catapult Sprint (Catapult Sports, Australia) and examined for errors. A total of $11 \%$ of the raw data was removed due to loss of contact between the HR monitor and skin or GPS unit. Further, the data was edited to only include running-based training. TRIMP was calculated for each training session according to the method used by Banister (6), where maximal HR was measured as the highest HR recorded during the 30-15 IFT. SRPE was calculated for each session by multiplying the participants' RPE by the duration of the training session in minutes.

\section{External TL Measures}

The raw GPS data was imported to Catapult Sprint (Catapult Sports, Australia) after each training session. Subsequently, only data from the runningbased training was used for analysis. The total distance and high-speed distance $(19.8 \mathrm{~km} \cdot \mathrm{h}$ 1) (14) for each session was calculated using the product software. Acceleration-based load (accload) was estimated using the average change in running velocity, multiplied by the training duration in seconds (17). High-metabolic power distance (HPD) was defined as distance covered whilst above $20 \mathrm{~W} \cdot \mathrm{kg}-1$, where metabolic power was estimated using methods described by Osgnach et al. (45). The average metabolic power was multiplied by body mass and training duration in seconds to give an estimate of metabolic work (Workmet) of a training session (45). Moreover, the mechanical work of a session was estimated by multiplying force by TD. Lastly, impulse was calculated to reflect the mechanical demands of training by multiplying force by the training duration in seconds (57) using equation 3. 


\section{Statistical Analysis}

Firstly, normal distribution was determined for the data using Shapiro-Wilk test for normality. The relationships between the internal and external TL were examined using repeated linear regression analyses. Correlation coefficients were interpreted as: $0.0-0.1=$ trivial; $0.1-0.3=$ small; $0.3-0.5=$ moderate; $0.5-0.7=$ large; $0.7-0.9=$ very large; 0.9 $0.99=$ nearly perfect; $1.0=$ perfect $(30)$. Two linear mixed model analyses were performed to generate the training efficiency models for TRIMP and SRPE. Internal TL (TRIMP or SRPE) was modelled as the dependent variable, training date as a repeated measure, and external TL variables with an effect size equal to or greater than moderate as random effects. A daily training efficiency score was calculated from the function of the relationship between internal and external TL.

Similarly, the effect of wellness on training efficiency was determined using two separate linear mixed model analyses. Training efficiency score was modelled as the dependent variable, training date as a repeated measure, and cumulative wellness score as a random effect. Data was analysed with SPSS 23 (IBM, Illinois, USA) using a threshold for statistical significance at a-level less than 0.05.

\section{RESULTS}

\section{Training Efficiency Model}

Significant correlations were observed between TRIMP and all measures of external TL, with effect sizes ranging from small to large. Moreover, significant small to large positive relationships were observed between sRPE and TD, HSD, Acc-load, HPD, WMet, and WMech. The results of the linear regression analyses are presented in Table 1.

Considering TRIMP, greater than moderate effect sizes were observed for TD, HSD, HPD, and WMet and these external load measures were subsequently included in the training efficiency model. Using the same rationale, TD, HSD, HPD, WMet, and WMech were included in the training efficiency model for SRPE. A slope coefficient was derived for each measure from the mixed model regression analyses (Table 1). The slope coefficients were used to solve the equation for the mixed model analyses which yielded a daily training efficiency score. The teams' daily training efficiency scores during the 6-week period is depicted in Figure 1, plotted against mean HPD.

\begin{tabular}{|c|c|c|c|c|c|}
\hline $\begin{array}{l}\text { Internal } \\
\text { Training Load } \\
\text { Measure }\end{array}$ & $\begin{array}{l}\text { External } \\
\text { training load } \\
\text { measure }\end{array}$ & $\begin{array}{l}\text { Correlation } \\
\text { coefficient }\end{array}$ & Effect size & $\begin{array}{l}\text { Significance } \\
\text { (p) }\end{array}$ & $\begin{array}{l}\text { Slope } \\
\text { coefficient }\end{array}$ \\
\hline \multirow[t]{7}{*}{ TRIMP } & TD & 0.573 & Large & $<0.001$ & 0.024 \\
\hline & $\mathrm{HSD}$ & 0.315 & Moderate & 0.001 & 0.020 \\
\hline & Acc-loadHPD & 0.169 & Small & 0.043 & \\
\hline & HPD & 0.311 & Moderate & 0.001 & 0.380 \\
\hline & $W_{\text {Met }}$ & 0.536 & Large & $<0.001$ & 0.003 \\
\hline & $W_{\text {Mech }}$ & 0.280 & Small & 0.002 & \\
\hline & Impulse & 0.167 & Small & 0.045 & \\
\hline \multirow[t]{7}{*}{ sRPE } & TD & 0.757 & Very large & $<0.001$ & 0.045 \\
\hline & $\mathrm{HSD}$ & 0.566 & Large & $<0.001$ & 0.078 \\
\hline & Acc-loadHPD & 0.154 & Small & 0.049 & \\
\hline & HPD & 0.618 & Large & $<0.001$ & 0.055 \\
\hline & $W_{\text {Met }}$ & 0.710 & Very large & $<0.001$ & 0.080 \\
\hline & $W_{\text {Mech }}$ & 0.329 & Moderate & $<0.001$ & 0.004 \\
\hline & Impulse & 0.139 & Small & 0.068 & \\
\hline
\end{tabular}

Table 1. Note. TD = total distance; HSD = high-speed distance; Acc-load = acceleration-based load; HPD = high-power distance; $\mathrm{W}_{\text {Met }}=$ metabolic work; $\mathrm{W}_{\text {Mech }}=$ mechanical work. 


\section{Cumulative wellness}

The wellness questionnaire achieved a compliance rate of $82 \%$. The median cumulative wellness score recorded was 9 (range $=5-13$ ) out of a maximum of 15 . The regression analyses did not discover a significant relationship between the training efficiency model for TRIMP and the cumulative wellness score ( $r=-0.046 ; p=0.336$; Figure 2$)$, or between the training efficiency model for SRPE and the cumulative wellness score $(r=-0.034 ; p=0.370$; Figure 3).

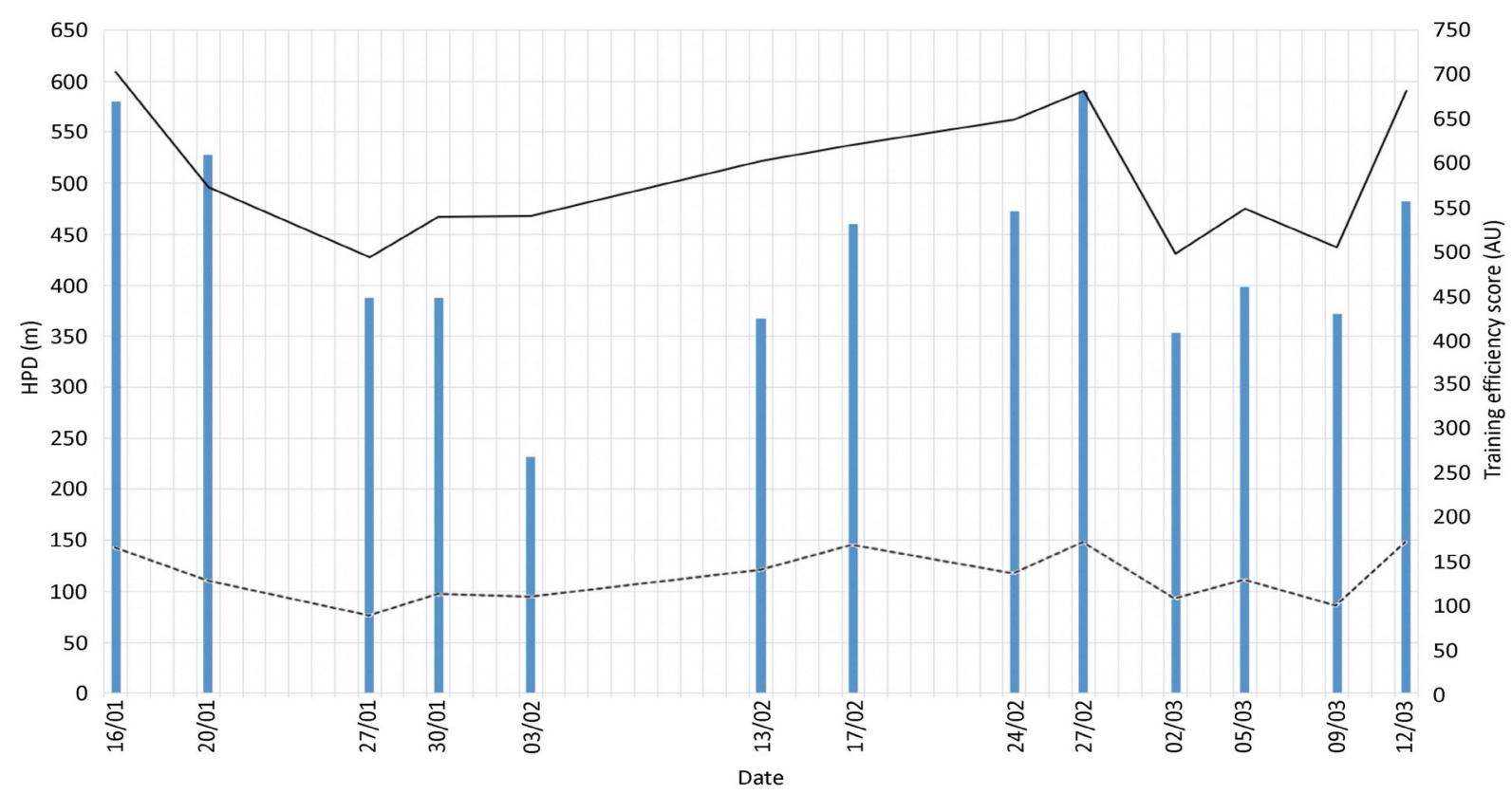

Figure 1. Team average daily training efficiency scores plotted against average daily high-power distance.

Note. Bar chart $=$ high-power distance; solid line = TRIMP training efficiency scores; dashed line $=\mathrm{sRPE}$ training efficiency scores.

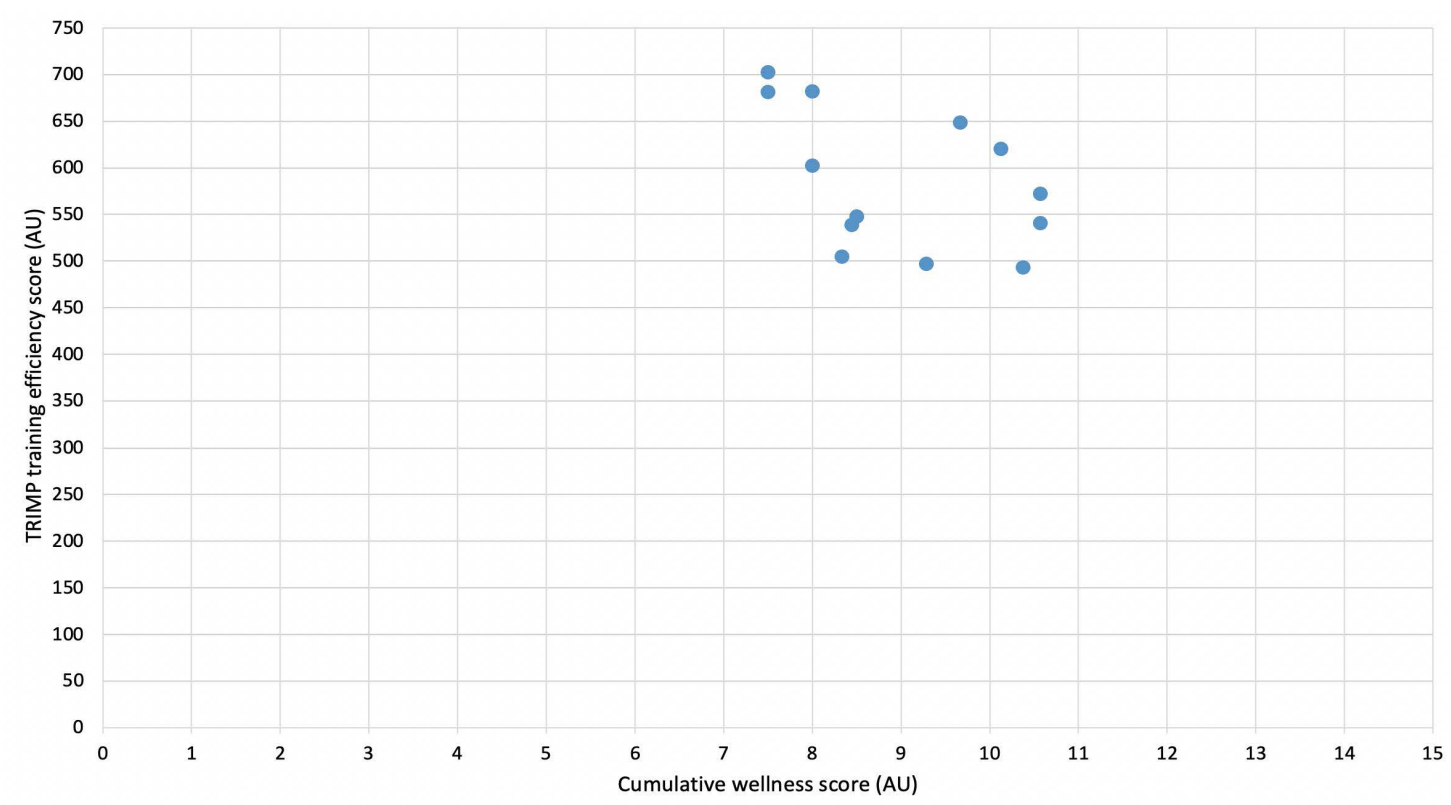

Figure 2. Correlation between TRIMP training efficiency and cumulative wellness 


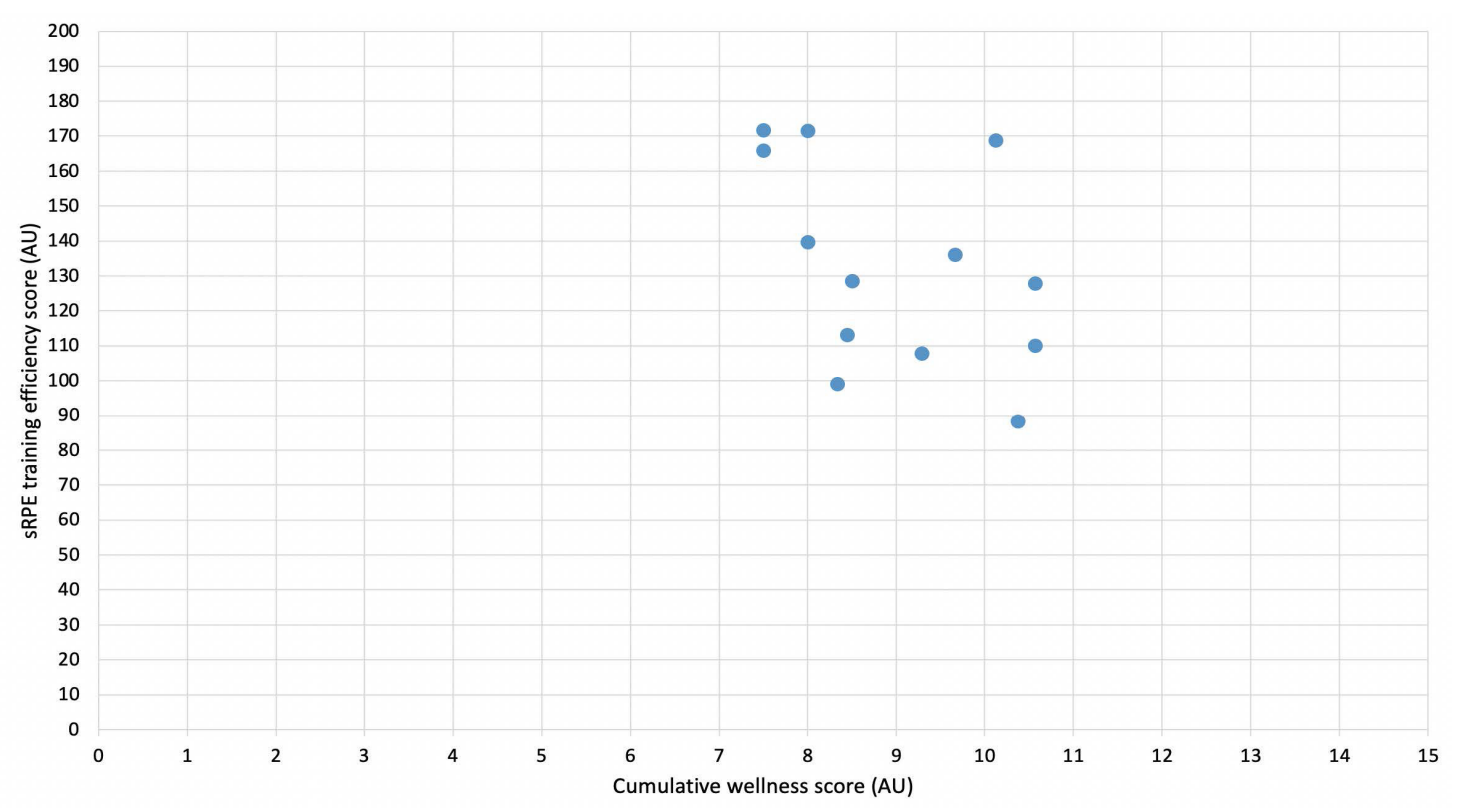

Figure 3. Correlation between sRPE training efficiency and cumulative wellness

\section{DISCUSSION}

The aim of the study was to examine the relationship between internal and external TL in field hockey in order to create a training efficiency model. Significant relationships were found between TRIMP and all measures of external TL, and between SRPE and six measures of external TL. Therefore, the first null hypothesis was partly rejected. The second hypothesis was rejected, as no relationships were found between the cumulative wellness score and either of the training efficiency models.

\section{Training Efficiency Model}

The training efficiency model presented here provided an integrated measure of training stimulus (external TL) and physical response (internal $T L$ ) to monitor training volume and intensity. The training efficiency scores recorded over the 6-week inseason period were exemplified in Figure 1. Considering external load alone (here: HPD), large variations were apparent in training stimulus. However, considering the training efficiency scores, integrated training stimulus and physical response stayed relatively similar throughout the period. During the in-season period teams aim to maintain fitness, peak for important matches, manage fatigue, and develop technical and tactical skills (43). Consequently, training intensity and volume are lower to account for a greater number of matches. The highest training efficiency scores were observed on January 16th and February 27th, after which the scores decreased. This is suggested to be due to an increase in $T L$ followed by a short taper allowing players to peak for the first game after the Christmas break and the Scottish Cup semi-final, which is in line with the recommendations for training periodisation by Mujika et al. (43). Smaller variations were seen in the SRPE model scores, compared to the TRIMP model. Therefore, the sRPE model may better reflect the TL experienced by players and be better suited to monitor in-season TL in men's field hockey.

Significant relationships were found between TRIMP and all measures of external TL (Table 1). Although only six of the relationships between SRPE and external TL (TD, HSD, Acc-load, HPD, Wmet, and Wmech) were significant, the correlations were stronger compared to TRIMP (Table 1). This further supports the idea that SRPE may be a more suitable TL monitoring method within the context of the study. Though large correlations have been reported between TRIMP and SRPE in elite football $(4,36)$, a weaker correlation has been observed during in-season training compared to periods of high-intensity training (47). The weighting factor (factor b) used to calculate TRIMP is intended to give similar weighting to a high volume of lowintensity activity and a low volume of high-intensity activity (6). However, due to this, internal TL may be overestimated when a greater amount of time is spent at high-intensity activity and underestimated when players spend a greater time doing lowintensity activity, compared to SRPE (9). Therefore, the internal TL may have been underestimated when TRIMP was used due to a lower training intensity 
during in-season training, whereas sRPE provided a more appropriate quantification of internal TL during this period.

Delaney, Duthie, et al. (18) recommended using TRIMP to monitor internal TL due to its stronger correlations with external TL measures, compared to SRPE. Conversely, the current study found stronger relationships for sRPE. The former study was conducted during pre-season, when training intensity is generally higher than in-season (34), and TRIMP may have better reflected demands of training. The authors concluded that prescribing external TL based on Wmet and Wmech would ensure similar internal TL across players of differing body mass, due to the strongest relationships being observed between TRIMP and Wmet $(r=0.95)$, and Wmech ( $r=0.96)$ (18). Wmech takes into account the energy cost of accelerations, decelerations, and change of directions, which are important factors in multidirectional sports like field hockey (14). Interestingly, a small relationship was found between Wmech and TRIMP in the current study $(r=0.280)$ and it was not included in the training efficiency model, suggesting that TRIMP did not take into account the demands of these activities in field hockey. Similarly, previous researchers have argued that TRIMP does not reflect the demands of intermittent sports $(3,32)$. The results of the current study are in agreement with Alexiou and Coutts (4), and Scott et al. (50) that sRPE may better reflect the demands of training of an intermittent nature.

Intermittent sports require sprints of high accelerations for good performance (14). Significant large positive correlations have been observed between the number of accelerations performed above 2.5 and $3 \mathrm{~m} \cdot \mathrm{s}-2$ and TRIMP ( $\mathrm{r}=0.58)$ and SRPE $(r=0.631)$ during in-season in football $(26,51)$. In support of the theory that SRPE better reflect overall training intensity than TRIMP during less intense training periods, these studies further reported that the number of accelerations performed per minute was significantly related to SRPE $(r=0.297)$ but not TRIMP $(26,51)$. However, in the current study, acc-load was not included in the training efficiency models due to the small effect sizes of the relationships between acc-load and internal TL. It is suggested that that the use of average acceleration to calculate acc-load did not reflect the demands of accelerations during the whole training sessions. Similarly, the correlations between impulse and the internal TL measurements did not reach moderate effect sizes, which was likely due to average acceleration not accurately reflecting the demands of training. Alternatively, using accumulated acceleration has been used to calculate Impulse Load has yielded a significant positive relationship with sRPE in football ( $r=0.84)$ (27). In contrast, Delaney, Duthie et al. (18) and Delaney, McKay et al. (19) found nearly perfect relationships between TRIMP and SRPE, and acc-load $(r=0.95$ and $r=0.93)$ and impulse $(r=0.95$ and $r=0.93)$ in rugby, and between TRIMP and impulse in football ( $r=0.93$ ). The aforementioned differences in playing activities and intensity between these sports and field hockey may explain the contradictory results of the current study. The training efficiency model provided a more comprehensive view of overall training load in field hockey than internal or external TL alone. The stronger relationships observed for SRPE and the limitations of TRIMP during less intense training periods suggests that this method provides a more relevant way of generating the model during inseason training. Due to the significant correlations previously observed between SRPE and various wellness items $(13,28)$, it was of interest to examine whether the training efficiency models were affected by acute changes in cumulative wellness scores.

\section{Cumulative Wellness}

The format of the wellness questionnaire was considered appropriate, reflected by the good compliance rate. However, the training efficiency scores were not affected by the players daily wellness state, as indicated by insignificant relationships between the cumulative wellness score and training efficiency scores. This is in agreement with Vescovi et al. (55) who did not discover a significant relationship between a cumulative wellness scores, including fatigue, stress, sleep, muscle soreness, training enjoyment, irritability, and overall health, and TeamTRIMP or sRPE in elite female hockey. Similarly, Delaney, McKay et al. (19) found trivial relationships between their TRIMP training efficiency model and sleep duration, perceived muscle soreness, and stress in women's football. (23). Conversely, Gallo et al. (24) utilised a simple ratio of external to internal TL and reported a small positive relationship between wellness and average speed:RPE ratio, and a moderate negative relationship between PlayerLoad slow:RPE ratio. Despite this, the use of linear modelling techniques to examine the relationship between wellness and $T L$ has been questioned, due to varying physiological responses to the same TL between players. Moreover, players with unfavourable wellness scores may maintain external TL variables they consider necessary whilst modifying other aspects of their training deemed 
less important to continue performing well (24). With this in mind, several external TL measures were included in the current training efficiency model, where players may have considered some of these critical for performance and others less important. Consequently, the daily changes in the included external TL measures may have occurred irrespective of changes in the players' wellness scores. Therefore, it is suggested that coaches do not modify TL based on acute changes in wellness. Nevertheless, wellness monitoring provides useful information on individual players' recovery state and may be used to notice trends toward undesirable outcomes such as injury, illness, non-functional overreaching, or poor performance (48).

\section{Limitations}

The results of the current study must be considered alongside its limitations. SRPE was recorded for a training session as a whole, whilst only runningbased training was considered for measurement of external TL. Though non-running-based training made up a small section of training sessions, this may have affected the subsequent statistical analysis. Moreover, the current study utilised Banister's TRIMP as it provided the most practical method for future use for the team. However, the generic weighting factor used does not take into account the varying training status of players (9). Using individualised weighting factors (i.e. iTRIMP; 40) may have provided a more accurate quantification of internal TL and warrants further research. Despite this, the participants in the current study were of similar fitness levels, reflected by their similar scores in the 30-15 IFT, and Banister's TRIMP should have provided an appropriate measurement. Lastly, players occasionally failed to respond to the wellness questionnaire, they were allowed to remove equipment due to discomfort, and there was loss of contact between the transmitter belt and GPS or between the belt electrodes and skin surface, resulting in incomplete data sets. Thus, participants' data for a training session was removed if locomotor data was missing from running-based drills. However, utilising linear mixed modelling allowed for longitudinal analysis with missing HR or wellness data.

\section{Practical Applications}

The training efficiency models presented in the current study presents methods for sports practitioners to monitor TL by integrating internal and external TL. Higher and lower scores indicate better and worse training efficiency, respectively. Consequently, the training efficiency scores may be used to assess whether the prescribed training is appropriate (i.e. if the goal is to maintain performance, training efficiency remains similar week to week). Based on the results of the current study, practitioners are recommended to use sRPE when calculating players training efficiency scores during in-season in field hockey. However, Banister's TRIMP proposes an acceptable method if practitioners choose to monitor $H R$. In Figure 1. the mean scores for the team was presented, however, training monitoring should be assessed on an individual basis to effectively monitor individual performance. Moreover, training efficiency does not appear to be affected by daily changes in wellness, and practitioners are therefore advised not to modify training based on acute changes in players' perceived wellness.

\section{Conclusion}

The findings of this study suggest that SRPE is a more appropriate training monitoring method during in-season training in field hockey than TRIMP, due to its stronger relationships with measures of external TL. Two integrated internal TL and external $\mathrm{TL}$ measures were presented to monitor male field hockey players' acute response to in-season training. The training efficiency models were not affected by acute changes in perceived wellness, suggesting that changes in training efficiency was due to other confounding factors. Despite a lack of concurrent validity between training efficiency scores and changes in fitness, the metric presented an easily understandable metric of TL. Again, training efficiency calculated using SRPE appeared to provide a better reflection of the TL performed by players. Collectively, this study recommends SRPE for monitoring TL and training efficiency to gain insight to the training status of male field hockey player during in-season training. 


\section{REFERENCES}

1. L Akenhead, R., \& Nassis, G.P. (2016). Training load and player monitoring in high-level football: Current practice and perceptions. International Journal of Sports Physiology and Performance, 11(5), 587-593. https://doi. org/10.1123/ijspp.2015-0331

2. Akubat, I., Barrett, S., \& Abt, G. (2014). Integrating the internal and external training loads in soccer. International Journal of Sports Physiology and Performance, 9(3), 457462. https://doi.org/10.1123/ijspp.2012-0347

3. Akubat, I., Patel, E., Barrett, S., \& Abt, G. (2012). Methods of monitoring the training and match load and their relationship to changes in fitness in professional youth soccer players. Journal of Sports Sciences, 30(14), 14731480. https://doi.org/10.1080/02640414.2012.712711

4. Alexiou, H., \& Coutts, A. J. (2008). A comparison of methods used for quantifying internal training load in women soccer players. International Journal of Sports Physiology and Performance, 3(3), 320-330. https://doi. org/10.1123/ijspp.3.3.320

5. Aughey, R. J. (2011). Applications of GPS technologies to field sports. International Journal of Sports Physiology and Performance, 6(3), 295-310. https://doi.org/10.1123/ ijspp.6.3.295

6. Banister, E. W. (1991). Modeling elite athletic performance. In J. D. Macdougal, H. A. Wenger, \& H. J. Green (Eds.), Physiological testing of the high-performance athlete (2nd ed., pp. 403-425). Human Kinetics.

7. Borg, G., Hassmén, P., \& Lagerström, M. (1987). Perceived exertion related to heart rate and blood lactate during arm and leg exercise. European Journal of Applied Physiology and Occupational Physiology 56(6), 679-685. https://doi.org/10.1007/bf00424810

8. Borresen, J., \& Lambert, M. (2009). The quantification of training load, the training response and the effect on performance. Sports Medicine, 39(9), 779-795. https://doi. org/10.2165/11317780-000000000-00000

9. Borresen, J., \& Lambert, M. I. (2008). Quantifying training load: A comparison of subjective and objective methods. International Journal of Sports Physiology and Performance, 3(1), 16-30. https://doi.org/10.1123/ ijspp.3.1.16

10. Brener, N. D., Billy, J. O. G., \& Grady, W. R. (2003). Assessment of factors affecting the validity of self-reported health-risk behavior among adolescents: evidence from the scientific literature. Journal of Adolescent Health, 33(6), 436-457. https://doi.org/10.1016/S1054$139 \times(03) 00052-1$

11. Buchheit, M. (2008). The 30-15 intermittent fitness test: Accuracy for individualizing interval training of young intermittent sport players. Journal of Strength and Conditioning Research, 22(2), 365-374. https://doi. org/10.1519/JSC.0b013e3181635b2e

12. Buchheit, M., \& Laursen, P. (2013). High-intensity interval training, solutions to the programming puzzle. Sports Medicine, 43(5), 313-338. https://doi.org/10.1007/s40279013-0029-x

13. Buchheit, M., Racinais, S., Bilsborough, J. C., Bourdon, P. C., Voss, S. C., Hocking, J., Cordy, J., Mendez-Villanueva, A., \& Coutts, A. J. (2013). Monitoring fitness, fatigue and running performance during a pre-season training camp in elite football players. Journal of Science and Medicine in Sport, 16(6), 550-555. https://doi.org/10.1016/j. jsams.2012.12.003

14. Buglione, A., Ruscello, B., Milia, R., Migliaccio, G. M.,
Granatelli, G., \& D'Ottavio, S. (2013). Physical and physiological demands of elite and sub-elite field hockey players. International Journal of Performance Analysis in Sport, 13(3), 872-884. https://doi.org/10.1080/24748668.2 013.11868695

15. Coutts, A. J., \& Reaburn, P. (2008). Monitoring changes in rugby league players' perceived stress and recovery during intensified training. Perceptual and Motor Skills, 106(3), 904-916. https://doi.org/10.2466/pms.106.3.904916

16. Coyne, J., Gregory Haff, G., Coutts, A., Newton, R., \& Nimphius, S. (2018). The current state of subjective training load monitoring - a practical perspective and call to action. Sports Medicine, 4(1), 1-10. https://doi. org/10.1186/s40798-018-0172-x

17. Delaney, J. A., Cummins, C. J., Thornton, H. R., \& Duthie, G. M. (2018). Importance, reliability, and usefulness of acceleration measures in team sports. Journal of Strength and Conditioning Research, 32(12), 3485-3493. https://doi org/10.1519/JSC.0000000000001849

18. Delaney, J. A., Duthie, G. M., Thornton, H. R., \& Pyne, D. B. (2018). Quantifying the relationship between internal and external work in team sports: development of a novel training efficiency index. Science and Medicine in Football, 2(2), 149-156. https://doi.org/10.1080/24733938. 2018.1432885

19. Delaney, J. A., McKay, B. A., Thornton, H. R., Murray, A., \& Duthie, G. M. (2018). Training efficiency and athlete wellness in collegiate female soccer. Sports Performance \& Science Reports, 1, 1-3. https://www.researchgate.net/ publication/323858599_Training_efficiency_and_athlete_ wellness_in_collegiate_female_soccer

20. Delfino, B. S., Nauta, J., Pols, M. J., Mechelen, W., \& Verhagen, E. A. L. M. (2018). Injuries in Dutch elite field hockey players: A prospective cohort study. Scandinavian Journal of Medicine \& Science in Sports, 28(6), 17081714. https://doi.org/10.1111/sms. 13065

21. Dellal, A., Owen, A., Wong, D. P., Krustrup, P., van Exsel, M., \& Mallo, J. (2012). Technical and physical demands of small vs. large sided games in relation to playing position in elite soccer. Human Movement Science, 31(4), 957-969. https://doi.org/10.1016/j.humov.2011.08.013

22. Foster, C., Hector, L. L., Welsh, R., Schrager, M., Green, M. A., \& Snyder, A. C. (1995). Effects of specific versus cross-training on running performance. European Journal of Applied Physiology, 70(4), 367-372. https://doi. org/10.1007/BF0086503

23. Gabbett, J. T., Whyte, D., Hartwig, T., Wescombe, H., \& Naughton, G. (2014). The relationship between workloads, physical performance, injury and illness in adolescent male football players. Sports Medicine, 44(7), 989-1003. https://doi.org/10.1007/s40279-014-0179-5

24. Gallo, T. F., Cormack, S. J., Gabbett, T. J., \& Lorenzen, C. $H$. (2016). Pre-training perceived wellness impacts training output in Australian football players. Journal of Sports Sciences, 34(15), 1445-1451. https://doi.org/10.1080/0264 0414.2015 .1119295

25. Gastin, B. P., Meyer, B. D., \& Robinson, B. D. (2013). Perceptions of wellness to monitor adaptive responses to training and competition in elite Australian football. Journal of Strength and Conditioning Research, 27(9), 2518-2526. https://doi.org/10.1519/JSC.0b013e31827fd600

26. Gaudino, P., Iaia, F. M., Strudwick, A. J., Hawkins, R. D., Alberti, G., Atkinson, G., \& Gregson, W. (2015). Factors influencing perception of effort (session rating of perceived exertion) during elite soccer training. International Journal of Sports Physiology and 
Performance, 10(7), 860-864. https://doi.org/10.1123/ ijspp.2014-0518

27. Gentles, J. A., Coniglio, C. L., Besemer, M. M., Morgan, J. M., \& Mahnken, M. T. (2018). The demands of a women's college soccer season. Sports, 6(1), 1-11. https://doi. org/10.3390/sports6010016

28. Govus, A. D., Coutts, A., Duffield, R., Murray, A., \& Fullagar, H. (2018). Relationship between pretraining subjective wellness measures, player load, and ratingof-perceived-exertion training load in American college football. International Journal o f Sports Physiology a nd Performance, 13(1), 95-101. https://doi.org/10.1123/ ijspp.2016-0714

29. Halson, S. (2014). Monitoring training load to understand fatigue in athletes. Sports Medicine, 44(Supplement 2), 139-147. https://doi.org/10.1007/s40279-014-0253-z

30. Hopkins, W. G. (2002). A scale of magnitudes for effect statistics. A new view of statistics, 502, 411. https://www. sportsci.org/resource/stats/effectmag.html

31. Ihsan, M., Tan, F., Sahrom, S., Choo, H. C., Chia, M., \& Aziz, A. R. (2017). Pre-game perceived wellness highly associates with match running performances during an international field hockey tournament. European Journal of Sport Science, 17(5), 593-602. https://doi.org/10.1080/174 61391.2017 .1301559

32. Impellizzeri, F. M., Marcora, S. M., \& Coutts, A. J. (2019). Internal and external training load: 15 years on. International Journal of Sports Physiology and Performance, 14(2), 270-273. https://doi.org/10.1123/ ijspp.2018-0935

33. Impellizzeri, F. M., Rampinini, E., Coutts, A. J., Sassi, A., \& Marcora, S. M. (2004). Use of RPE-based training load in soccer. Medicine \& Science in Sports \& Exercise, 36(6), 1042-1047. https://doi.org/10.1249/01 MSS.0000128199.23901.2F

34. Jeong, T.-S., Reilly, T., Morton, J., Bae, S.-W., \& Drust, B. (2011). Quantification of the physiological loading of one week of "pre-season" and one week of "in-season" training in professional soccer players. Journal of Sports Sciences, 29(11), 1161-1166. https://doi.org/10.1080/02640414.201 1.583671

35. Jones, B., Hamilton, D., K., \& Cooper, C., E. (2015). Muscle oxygen changes following Sprint Interval Cycling training in elite field hockey players. PLoS ONE, 10(3), 1-17. https://doi.org/10.1371/journal.pone.0120338

36. Kelly, D. M., Strudwick, A. J., Atkinson, G., Drust, B., \& Gregson, W. (2016). The within-participant correlation between perception of effort and heart rate-based estimations of training load in elite soccer players. Journal of Sports Sciences, 34(14), 1328-1332. https://doi.org/10.1 080/02640414.2016.1142669

37. Kim, T., Cha, J., \& Park, J. (2018). Association between in-game performance parameters recorded via global positioning system and sports injuries to the lower extremities in elite female field hockey players. Cluster Computing-The Journal Of Networks Software Tools And Applications, 21(1), 1069-1078. https://doi.org/10.1007/ s10586-016-0690-6

38. Lacome, M., Simpson, B., Broad, N., \& Buchheit, M. (2018). Monitoring players' readiness using predicted heart-rate responses to soccer drills. International J ournal of Sports Physiology and P erformance, 13(10), 1273-1280. https://doi.org/10.1123/ijspp.2018-0026

39. Lucía, A., Hoyos, J., Carvajal, A., \& Chicharro, J. (1999). Heart rate response to professional road cycling: The Tour de France. International journal of sports medicine, 20(3), 167-172. https://doi.org/10.1055/s-1999-970284
40. Manzi, V., Iellamo, F., Impellizzeri, F., D’Ottavio, S., \& Castagna, C. (2009). Relation between individualized training impulses and performance in distance runners. Medicine \& Science in Sports \& Exercise, 41(11), 20902096. https://doi.org/10.1249/MSS.0b013e3181a6a959

41. McLaren, S., Macpherson, T., Coutts, A., Hurst, C., Spears, I., \& Weston, M. (2018). The relationships between internal and external measures of training load and intensity in team sports: A meta-analysis. Sports Medicine, 48(3), 641-658. https://doi.org/10.1007/s40279-017-0830-z

42. McMahon, E. G., \& Kennedy, A. R. (2019). Changes in player activity profiles after the $2015 \mathrm{FIH}$ rule changes in elite women's hockey. Journal of Strength and Conditioning Research, 33(11), 3114-3122. https://doi. org/10.1519/JSC.0000000000002405

43. Mujika, I., Halson, S., Burke, L. M., Balagué, G., \& Farrow, D. (2018). An integrated, multifactorial approach to periodization for optimal performance in individual and team sports. International Journal of Sports Physiology and Performance, 13(5), 538-561. https://doi.org/10.1123/ ijspp.2018-0093

44. Nicolella, D. P., Torres-Ronda, L., Saylor, K. J., \& Schelling, X. (2018). Validity and reliability of an accelerometer-based player tracking device. PLoS ONE, 13(2), 1-13. https://doi.org/10.1371/journal.pone.0191823

45. Osgnach, E. C., Poser, E. S., Bernardini, E. R., Rinaldo, E. R., \& Di Prampero, E. P. (2010). Energy cost and metabolic power in elite soccer: A new match analysis approach. Medicine \& Science in Sports \& Exercise, 42(1), 170-178. https://doi.org/10.1249/MSS.0b013e3181ae5cfd

46. Parrado, E., Cervantes, J., Pintanel, M., Rodas, G., \& Capdevila, L. (2010). Perceived tiredness and heart rate variability in relation to overload during a field hockey World Cup. Perceptual and Motor Skills, 110(3), 699-713. https://doi.org/10.2466/pms.110.3.699-713

47. Perrotta, A. S., Held, N. J., \& Warburton, D. E. R. (2017). Examination of internal training load parameters during the selection, preparation and competition phases of a mesocycle in elite field hockey players. International Journal of Performance Analysis in Sport, 17(5), 813-821. https://doi.org/10.1080/24748668.2017.1402284

48. Saw, A. E., Main, L. C., \& Gastin, P. B. (2015). Monitoring athletes through self-report: Factors influencing implementation. Journal of Sports Science and Medicine, 14(1), 137-146. https://link-gale-com. ezproxy.is.ed.ac.uk/apps/doc/A500969355/AONE?u=ed_ itw\&sid=AONE\&xid=37df09b9

49. Saw, A. E., Main, L. C., \& Gastin, P. B. (2016). Monitoring the athlete training response: subjective self-reported measures trump commonly used objective measures: a systematic review. British Journal of Sports Medicine, 50(5), 281-291. https://doi.org/10.1136/ bjsports-2015-094758

50. Scott, B. R., Lockie, R. G., Knight, T. J., Clark, A. C., \& Janse de Jonge, X. A. K. (2013). A comparison of methods to quantify the in-season training load of professional soccer players. International Journal of Sports Physiology and Performance, 8(2), 195-202. https://doi.org/10.1123/ ijspp.8.2.195

51. Silva, D. P., Santos, M. E., Grishin, M. M., \& Rocha, M. J. (2018). Validity of heart rate-based indices to measure training load and intensity in elite football players. Journal of Strength and Conditioning Research, 32(8), 2340-2347. https://doi.org/10.1519/JSC.0000000000002057

52. Taylor, K. L., Chapman, D. W., Cronin, J. B., Newton, M. J., \& Gill, N. (2012). Fatigue monitoring high performance sport: a survey of current trends. Journal of Australian 
Strength and Conditioning, 20(1), 12-23. https://doi. org/10.1017/CBO9781107415324.004

53. Taylor, R. J., Sanders, D., Myers, T., Abt, G., Taylor, C. A., \& Akubat, I. (2018). The dose-response relationship between training load and aerobic fitness in academy rugby union players. International Journal of Sports Physiology and Performance, 13(2), 163-169. https://doi. org/10.1123/ijspp.2017-0121

54. Varley, M. C., Gabbett, T., \& Aughey, R. J. (2014). Activity profiles of professional soccer, rugby league and Australian football match play. Journal of Sports Sciences, 32(20), 1858-1866. https://doi.org/10.1080/02640414.201 3.823227

55. Vescovi, J. D., Klas, A., \& Mandic, I. (2019). Investigating the relationships between load and recovery in women's field hockey - Female Athletes in Motion (FAiM) study. International Journal of Performance Analysis in Sport, 19(5), 672-682. https://doi.org/10.1080/24748668.2019.16 47731

56. Weaving, D., Whitehead, S., Till, K., \& Jones, B. (2017). Validity of real-time data generated by a wearable microtechnology device. Journal of Strength and Conditioning Research, 31(10), 2876-2879. https://doi. org/10.1519/JSC.0000000000002127

57. Winter, E. M., Abt, G., Brookes, F. B. C., Challis, J. H., Fowler, N. E., Knudson, D. V., Knuttgen, H. G., Kraemer, W. J., Lane, A. M., van Mechelen, W., Morton, R. H., Newton, R. U., Williams, C., \& Yeadon, M. R. (2016). Misuse of "power" and other mechanical terms in sport and exercise science research. The Journal of Strength \& Conditioning Research, 30(1), 292. 